\title{
THE EFFECTIVENESS IN THE USE OF INSTAGRAM IN THE PROMOTION OF B2B COMPANIES
}

\author{
Aleksey A. Nikitin ${ }^{1}$ \\ Tatyana I. Nikitina ${ }^{2}$ \\ Irina M. Kravchenko ${ }^{3}$
}

\begin{abstract}
This paper contains data from on social networks, the goals of statistical studies of foreign agencies on the use of social networks in promoting companies of the B2B segment (Business to business) and their effectiveness. The emphasis was placed on the social network Instagram, as it is one of the fastest-growing platforms for marketing and it has fundamental differences from other social networks. As the main methods for conducting the study, non-participant observation, monitoring of articles and results of marketing research, a comparative analysis of Instagram accounts of B2B promoting $\mathrm{B} 2 \mathrm{~B}$ companies, their target audience, the main types of content and other features of maintaining an account for using the Instagram platform as an effective marketing tool were identified and described. As a result of the analysis of statistical data obtained within the framework of various large studies and successful cases on the natural promotion of Instagram accounts of world B2B companies, conclusions were drawn about the effectiveness of using the social network Instagram for the B2B segment.
\end{abstract} companies and quantitative content analysis were used. It is assumed that the chosen methodology most adequately reflects the real specifics of the promotion process in the segment selected for the study. In the process of studying articles of promotion specialists

Keywords: Instagram, SMMmarketing, social networks, B2B-sphere, companies, promotion.

\section{Introduction}

\footnotetext{
${ }^{1}$ Kazan Federal University. Alexey011281@mail.ru,

${ }^{2}$ Kazan Federal University. Tatyana_shreya@mail.ru

${ }^{3}$ Kazan Federal University. Alexey011281@mail.ru, Tatyana_shreya@mail.ru
} 
Over the past 10 years, social networks have penetrated very deeply into human life. Initially, they were created for communication and networking of people around the world. Sites developed, accumulated an audience, and advanced businessmen saw this as an opportunity to get profit. The business began to penetrate social networks and the platforms themselves began to be adjusted, developed and built-in new functions to promote the business and ease of sales. Not only ordinary people started creating accounts and pages on social networks, but also shops, restaurants, fitness clubs, photo studios, beauty salons and many other B2C segment participants ("business to customer", business for a client).

Social networks which are mainly used as part of SMM promotion are Facebook, Instagram, Twitter, Youtube, and LinkedIn. This paper will only consider the social network Instagram, as it attracts with its rapid growth and an expanded set of tools for promotion.

Instagram is a mobile social network for posting photos and videos, which may be accompanied by text if desired. Launched on October 6, 2010, in 2012 it was bought by the "giant" Facebook for $\$ 1$ billion. Advertising tools in the social network were added in September 2015 and in the same year brought 595 million dollars in revenue. According to the beginning of 2019, more than 1 million advertisers are already on the platform [1].

$41 \%$ of the Instagram social network users are 24 years old or younger. Due to the visual nature of the application and the high degree of user engagement, Instagram is now a valuable tool for social media marketing.

As of June 2018, the social network Instagram has 1 billion active users per month around the world [2]. The application is one of the most popular social networks in the world and a very fast growing platform for business development. According to analysts, in 2019, about $25 \%$ of all Facebook advertising revenue will be earned on Instagram. By 2020, Instagram's share in total revenue will grow to $30 \%$. [3]

Following the fashion, at the time of the growing popularity and development of social networks, larger companies working in the $\mathrm{B} 2 \mathrm{~B}$ sphere ("business to business") also stepped into them, but the result was not so 
successful. When developing accounts on social networks, many did not take into account that the communication strategy should be built in a special way (including on Instagram).

Most companies initially open accounts only because they should be: post links to them on the site, ask their partners and acquaintances to subscribe, occasionally fill them with content. There is no benefit in doing so. At the same time, many heads of B2B companies have logical questions:

1) Is it worth the time and money to maintain the social networks of the company?

2) Is there any result from their use?

3) Can this increase the sale of the company's products/services?

Those who, for various reasons, do not find answers to these questions, leave their social networks unattended and, thereby, losing one of the very effective channels of communication with the audience.

For the efficient management of B2B accounts, it is necessary to build a special strategy taking into account the specific target audience and promotion tasks.

\section{Methods}

When writing the paper, the authors used such methods of collecting and analysing the information as observation, monitoring, comparative analysis and content analysis. The observation method was used during the personal experience in maintaining an Instagram account for a B2B segment company. The Instagram social network was monitored to identify company business accounts. As a comparison, case studies were conducted with the successful and unsuccessful use of the Instagram social network in promoting B2B companies. In the process of content analysis, articles by experts on promotion in social networks, cases of successful companies and directly company accounts in the social network Instagram were studied.

\section{Results and discussions}

Before starting the analysis of content, it is worth noting that SMM promotion for companies in the $\mathrm{B} 2 \mathrm{~B}$ sphere has different goals from those that are highlighted in promoting $\mathrm{B} 2 \mathrm{C}$ companies. 
The main goals of promoting social networks of a B2B-segment company are:

1. Creating a positive image of the company;

2. Dissemination of important information about the company;

3. Gaining audience loyalty;

4. Search for new employees;

5. Increase traffic to the site;

6. Attracting customers through a demonstration of the qualifications of employees and the image of the company, through unobtrusive removal of objections and elimination of pain.

The segmentation of the target audience of $\mathrm{B} 2 \mathrm{~B}$ companies is also different. It is worth noting the main target groups of such companies [4]:

1) Decision-makers in client companies (top managers);

2) Employees of client companies whose responsibilities include finding potential suppliers of complex products;

3) Potential company employees.
372

SMM-specialists highlight the benefits of working with an audience in social networks in comparison with working at professional events [5]:

- $\quad$ Reaching an audience is definitely greater than can be handled at industry exhibitions.

- The cost of publications is minimum due to use of social networks for free and spending money only on creating high-quality content or launching advertising, which, at the same time, is several times cheaper than through traditional channels (print media, television, radio).

- The opportunity to tell their story and build a dialogue with a potential client; taking a long and deliberate decision to cooperate with a company is typical for B2B; so longterm interaction increases the likelihood that a client will be led to a contract.

- A large set of available tools - social networks allow us to use various types of content: write texts, upload photos, share videos, shoot live broadcasts and communicate with the audience.

The research company CMO Survey, in collaboration with the School of Business Fuqua under Duke 
University and with the company Eloqua, conducted a global study [6] of the current state of $\mathrm{B} 2 \mathrm{~B}$ marketing and presented the following data:

- $10-12 \%$ of the total budget of large B2B companies goes to marketing, of which $8-10 \%$ go to work with social networks;

- $\quad 7.5-9 \%$ of sales come to B2B companies from the Internet, every second of these companies evaluates the results of their presence on social networks as "extremely positive";

- about $10 \%$ of the advertising budget of B2B business in North America goes to work with the social network Facebook and Instagram;

- The presence of B2B companies in social networks increases their sales by an average of $10 \%$.

Most of the companies surveyed assess their presence on social networks as an effective way of promotion and intend to draw up their advertising budget in 2019 in such a way as to increase SMM expenses by $20 \%$.

The 10th annual Social Media Examiner study [7] surveyed more than 5,700 marketing experts from around the world in various fields, including manufacturing, industrial products, and
373

various other B2B industries. This study provides a fairly broad view of what is happening on social networks.

- For $64 \%$ of marketing experts, managing social networks is just one of their responsibilities. Only about $36 \%$ of marketing experts work on social networks on an ongoing basis. The remaining two-thirds should do this in addition to their other duties. Considering how much time and effort is required for competent integrated promotion in social networks, this explains the fact that many pages of B2B companies in social networks are conducted irregularly and do not give the effect that they could give.

- $87 \%$ of respondents believe that their business receives more attention from social networks.

- $78 \%$ of marketing experts who use social networks for two or more years say about an increase in traffic to their websites, and $83 \%$ who use social networks for more than 5 years "fully agree" or "agree" with this.

- 66\% of marketing experts actively use Instagram. This social network surpassed Twitter and LinkedIn and became the second most popular. 
- $63 \%$ of marketing experts use video content in their marketing on social networks. Almost two-thirds of marketing experts use videos in their marketing on social networks, $23 \%$ use the opportunity to broadcast live.

Todd Clark, a copywriter and co-founder of the service for working with media platforms, provides some more static data on the work of the business on the social network Instagram [8]:

- $71 \%$ of US companies use Instagram, replacing Twitter, which was once considered the main social network for companies;

- Currently, 25 million business profiles are based on the platform and more than 200 million users visit at least one business profile every day;

- $80 \%$ of users follow at least one business;

- $75 \%$ of users visit the company's website after viewing the brand post because Instagram is more accessible and there is the opportunity to show the product in action;

- Every month, 2 million active advertisers are present on Instagram. And this is a great business opportunity to keep in touch with the company's audience.

SMM specialists identify the following areas of suitable content for placement on a B2B page [9]:

- Reputational. This is one of the best ways to show the world that the company is a professional in their field. The main motive that needs to be conveyed through publications is: "this company is a very reliable partner";

- Useful. Short checklists, guides or a list of tips that company specialists can share for free. Thus, the company shows its experience and demonstrates the level of qualification in the affairs of the field;

- Informational. Company news, image statements of TOP management, the use of brand journalism - an offer to potential and real customers to communicate with the company and get acquainted with its strengths.

Instagram is not as simple as Twitter or Facebook, where it's easy enough to share relevant content for industry participants and receive feedback. Given the peculiarity of this social network, namely the mandatory use of graphic material (photo or video), creativity and patience are required. You 
need to be more expressive, like most popular people's accounts. Subscribers want to feel that they have something in common with the company. Basically, this should not be directly related to sales or conversion, and it is unlikely to be able to instantly track the effect, but as soon as there are a lot of subscribers, it is felt. This definitely helps to create the right impression for current and future customers. [10]

Some experts [4] recommend using the Instagram platform as a place to tell the story of the company if this is part of the marketing strategy. This is suitable for non-strict $\mathrm{B} 2 \mathrm{~B}$ companies. An Instagram account is perfect for demonstrating oneself as an open and innovative company, where interesting and fun people work, who are easy to interact with. Perhaps this will not lead to wealthy customers, but it will definitely give an additional advantage for demonstrating the life of the company. If the corporate culture in the company is at a sufficient level, then employees who are active users of social networks will be happy to praise the organization at no extra charge and recommend each potential client to work with it.
375

Examples of Instagram accounts of the largest world companies that surprise the audience with their creative approach:

1) The global advertising and marketing agency Gray shows how B2B companies can expand the boundaries of what's possible on social networks. The description of the agency's account tells about their features: "Every week, one person from our office in New York takes our Instagram to share what inspires him/her. Oh, and all that in shades of grey. Subscribe, please!".To be a subscriber of their account is the same as being a spectator of a television series, where each week is a new episode, which is shot from the point of view of different characters. And the account is designed in the style of the company, even despite the fact that the "owner" is constantly changing. In this style of conducting a business account, the agency shows its audience the level of creativity of its employees and the unusual approach to the work of the entire company: since they trust the account in different employees, it means they work together as a single organism. And it definitely improves their reputation in the eyes of customers. 
2) The technology giant "IBM", being a well-established brand with a wide audience, publishes posts in the company's account that are aimed at different target groups - from technically savvy specialists to fans of the brand. Photographs combine technology and visual beauty. That part of the audience, which is professionally versed in engineering and mechanics, evaluates the technical part of the information, while the rest sees beautiful patterns and non-standard camera angles in photographs of wires, boards and endless codes. By mixing inspiration and storytelling, IBM shows off its proud heritage and authority in technology. [11]

3) The largest freight shipping company FedEx works all over the world. Their Instagram account very competently tells the various stories of their couriers around the world. Using exclusively user-generated content, with various levels of image quality, may seem like a risky strategy, but in the case of FedEx, it worked out perfectly. Encouraging people to write company references wherever they see them is a reward for keeping the brand in the field of view of all aspiring photographers and bloggers who want their photos to be posted on their FedEx page on Instagram. This activity contributes to the constant flow of content, which in turn inspires more people to participate in it. Also, the FedEx account shows one of its key messages to the audience: their delivery services are available anywhere in the world.

\section{Summary and Conclusions}

Social networks are now present in the life of almost every socially adopted person. For several years, Facebook, Youtube and Instagram are not just platforms for exchanging information between people, but fullfledged marketing platforms for selling goods and services.

It is proved that the business belonging to the $\mathrm{B} 2 \mathrm{C}$ segment is successfully developing in social networks and pays great attention to SMM promotion. B2B companies can also develop in social networks and receive orders, showing their serious and complex activities unusually, attracting an audience, gaining their trust and building a positive image.

The research results show that the experience of $\mathrm{B} 2 \mathrm{~B}$ companies in 
using social networks is positive: customer loyalty is increasing, sales are growing, and managers plan to increase the part of the budget allocated to SMM.

The social network Instagram, which is by the most of ordinary people considered to be a platform with an audience of exclusively "girls of 15-20 years old", has actually changed a long time ago and has become a huge platform for the dynamic development of business. It requires a special, creative and unusual approach to account management, thereby enabling the company to reveal itself to customers conversely, and thereby win the attention of new target groups.

But we must remember that we must be able to use even the most powerful "weapons" correctly. Incorrect goal setting, incorrect selection of tools and determining sites in the development of the SMM strategy leads to that the account becomes either a summary of news about the company's activities or a "personal" blog that tells about the company to its employees and close partners. By trial and error, it is necessary to identify which type of content is more suitable for the company and demonstrate its specialization, and refuse to use inefficient sites, redirecting the flow to more successful channels.

\section{Acknowledgements}

The work is carried out according to the Russian Government Program of Competitive Growth of Kazan Federal University.

\section{References}

Kudentsova R. Selected Instagram statistics: what do we have by 2018 ? [Electronic resource] URL: https://rusability.ru/internetmarketing/smm/otbornaya-instagramstatistika-chto-my-imeem-k-2018/ [access date: 03/10/2019]

Number of monthly active Instagram users from January 2013 to June 2018 (in millions) [Electronic resource] URL: https://www.statista.com/statistics/2535 77/number-of-monthly-activeinstagram-users/ [access date: 03/05/2019]

Kolowich L. The Ultimate List of Instagram Stats [2019]. [Electronic resource]

URL: https://blog.hubspot.com/marketing/inst agram-stats [access date: 03/10/2019] 
Lukyanov K. Do B2B brands need SMM and how to use it correctly? [Electronic resource]

URL:

https://www.likeni.ru/analytics/nuzhen-

li-b2b-brendam-smm-i-kak-pravilno-

ego-ispolzovat/ [access date:

03/05/2019]

Ulitovsky A. How to use social networks to promote B2B business in 2019?

[Electronic resource] URL: http://www.pro-smm.com/socialnyeseti-dlya-b2b-2019/ [access date: 03/05/2019]

Results by Firm and Industry Characteristics / The CMO Survey. 2018. [Electronic resource] URL: https://cmosurvey.org/wpcontent/uploads/sites/15/2018/08/The_C MO_Survey-

Results_by_Firm_and_Industry_Charac teristics-Aug-2018.pdf [access date: 03/10/2019]

Stelzner M.A. 2018 social media marketing industry report. How marketing experts are using social media to grow their business / Social Media Examiner. - 2018. [Electronic resource] URL: https://www.socialmediaexaminer.com/ social-media-marketing-industry-report2018/ [access date: 03/10/2019]

Clarke T. 22+ Instagram Stats That Marketing experts Can't Ignore This Year. [Electronic resource] URL: https://blog.hootsuite.com/instagramstatistics/ [access date: 03/06/2019] SMM-promotion for business (B2B). [Electronic resource] - URL: https://smm.artox-media.ru/smm-dlyab2b/ [access date: 03/06/2019]

Kononenko K. 7 Successful B2B Instagram Marketing Strategies. [Electronic resource] - URL: https://databox.com/instagrammarketing-strategies-b2b [access date: 03/06/2019]

Cole S. Four great B2B company Instagram accounts \& why they work so well. [Electronic resource] - URL: https://econsultancy.com/four-greatb2b-company-instagram-accounts-andwhy-they-work-so-well/ [access date: 03/06/2019] 